\title{
Design and Analysis of Scissor Lifting System by Using Finite Elements Method
}

\author{
Cengiz Görkem Dengiz, Mahmut Can Şenel', Kemal Yıldızlı, Erdem Koç \\ Mechanical Engineering Department, Faculty of Engineering, Ondokuz Mayis University, Turkey
}

Copyright@2018 by authors, all rights reserved. Authors agree that this article remains permanently open access under the terms of the Creative Commons Attribution License 4.0 International License

\begin{abstract}
Scissor-type systems are frequently used as lifting systems in the industry. These systems are mainly preferred to do maintenance, repair, and clean. In this study, the design and analysis of a scissor lift system were performed with having a load carrying capacity of $500 \mathrm{~kg}$ and a working height of $2 \mathrm{~m}$. The solid model and assembly of the system have been developed by the SolidWorks program. The structural analysis of the system was also investigated with the help of the same program i.e. stress, deflection, and safety factor values of system elements were obtained. As a result of the analyses, it was concluded that the system designed could safely be used during load/unload operations.
\end{abstract}

Keywords Lifting System, Finite Elements, Static Analysis, Deformation, Safety Factor

\section{Introduction}

Lifting systems are generally used for purposes of lifting a load or providing at unreachable heights [1]. Nowadays, many lifting systems are designed to be used for various purposes in industry. These systems can be used in multi-purpose applications and a range of services such as cleaning services, maintenance-repair activities, load lifting and lowering activities. Airports and indoor stadium are examples of these. Lifting systems can be classified as telescopic lifts, articulated lifts, and scissor lifts [2, 3].

The telescopic lifting systems are mainly the same as the operating principle of the fire escape stairway in fire brigade vehicles. These types of systems are a kind of maintenance-repair vehicle that can carry one or two people with a maximum platform height of $20-30 \mathrm{~m}$. The system is driven by electric motor and operated by chain. Also, these systems are not very safe due to the lack of hydraulic system. Articulated maintenance lifts are operated by a hydraulic drive which can move in $x-y-z$ coordinates. These systems are safer than telescopic lifting systems. Also, the systems are not designed to lift loads and these systems carry only one person on the platform. The working height of them is extremely high $[3,4]$. The most popular lifting systems in the industry are scissors lifting systems. These systems are especially used for maintenance-repair and cleaning. In the scissors lifting systems, the platforms are elevated by opening the scissors which are connected to each other by hydraulic cylinder. Each platform has a certain carrying and height capacity [1, 2]. In the mechanical design of the platform, the sizes of profiles, the selection of hydraulic cylinder and electric motor are very important in terms of user safety.

In this study, a scissors lifting system carrying a maximum load of $500 \mathrm{~kg}$ and having a working height of $2 \mathrm{~m}$ was designed. Solid model of system parts was modeled in SolidWorks program and assembled in the same program. In addition, static analysis of system has been performed by finite elements model in the SolidWorks.

\section{Design and Analysis of Scissor Lifting System}

\subsection{The General Properties of Designed System}

The load carrying capacity and the working height of the designed scissor lifting system were determined as $500 \mathrm{~kg}$ and $2 \mathrm{~m}$, respectively. The system has been designed as double scissors on the both sides and the connection of the scissors was provided by pins and segments as shown in Figure 1. Scissors used in the system are hollow having a rectangular profile. The size of the scissor profile is determined as $80 \times 40 \times 5 \mathrm{~mm}$. The size of cylindrical pins in the system is detected as $\varnothing 40 \times 120 \mathrm{~mm}$ in order to carry the load safely. The opening and closing of the system are provided by wheels moving on the rails. 


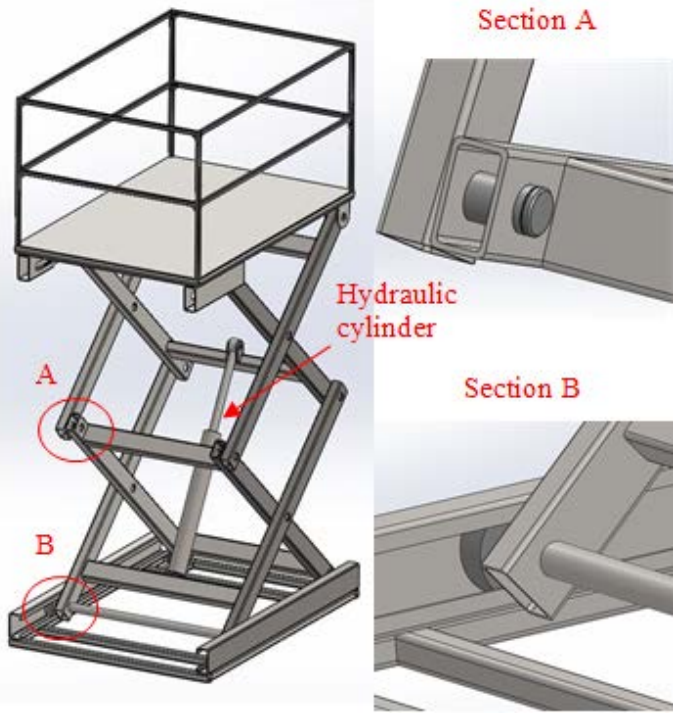

Figure 1. Perspective views of scissor lift system

St37 (S235JR) steel was used as the materials of profiles in the scissor lifting system. Also, St50 (E295) steel was preferred as pins material in the system. The mechanical properties of materials used were given in Table 1 . These materials are commonly used in manufacturing industry due to the low cost and easy supply. The strength of St50 material is better than St37 material. Hence, St50 and St37 steel were used as material in pins and scissor profiles, respectively.

Table 1. Mechanical properties of materials in system [5]

\begin{tabular}{|c|c|c|c|}
\hline Mechanical Properties & Symbol & St37 & St50 \\
\hline Yield strength (MPa) & $\sigma_{\mathrm{Y}}$ & 235 & 275 \\
\hline Tensile strength (MPa) & $\sigma_{\mathrm{F}}$ & 360 & 470 \\
\hline Elasticity modulus (GPa) & E & 210 & 210 \\
\hline Shear modulus (GPa) & G & 79 & 79 \\
\hline Poisson rate & $\vartheta$ & 0.28 & 0.28 \\
\hline Density $\left(\mathrm{kg} / \mathrm{m}^{3}\right)$ & $\rho$ & 7800 & 7800 \\
\hline
\end{tabular}

Double acting cylinder was used in the scissor lifting system as shown in Figure 2. The hydraulic cylinder has a diameter of $70 \mathrm{~mm}$ with $400 \mathrm{~mm}$ stroke. Hydraulic pump used in the system is gear pump type which is operated at 116 bar. The capacity of hydraulic oil tank is approximately $40 \mathrm{l}$ in the hydraulic system. The pump pressure value (116 bar) was determined by regarding the diameter of hydraulic cylinder and the maximum piston force $\left(\mathrm{F}_{\mathrm{p}}\right)$.

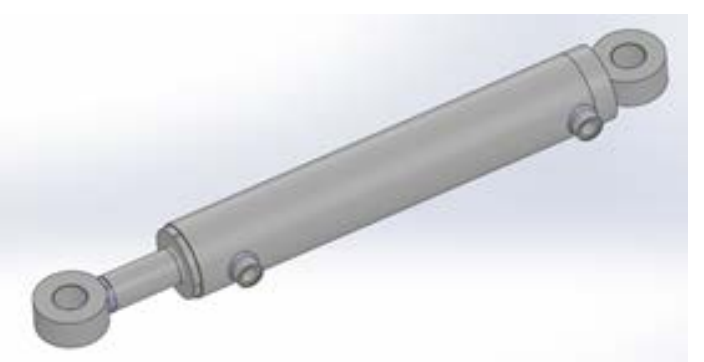

Figure 2. The designed hydraulic cylinder for system
The hydraulic circuit of scissor lifting system was created with the help of Fluid-Sim Hydraulic Package Program (Figure 3). The circuit is mainly consisted of a pressure unit (1), an oil filter (2), a pressure sequencing valve (3), a 4-way 3-position (4/3) directional control valve (4), a bidirectional flow control valve (5), a double acting hydraulic cylinder (6), and a hydraulic accumulator (7).

The system sends the pressurized oil to the pressure sequencing valve through pressure unit and the filter. The fluid oil open the pressure sequence valve and it sends to directional control valve and hydraulic accumulator under working pressure. After hydraulic accumulator has been charged to a sufficient pressure, hydraulic cylinder moves with changing the position of the directional control valve. The speed of the hydraulic cylinder can be controlled by a bidirectional flow control valve.

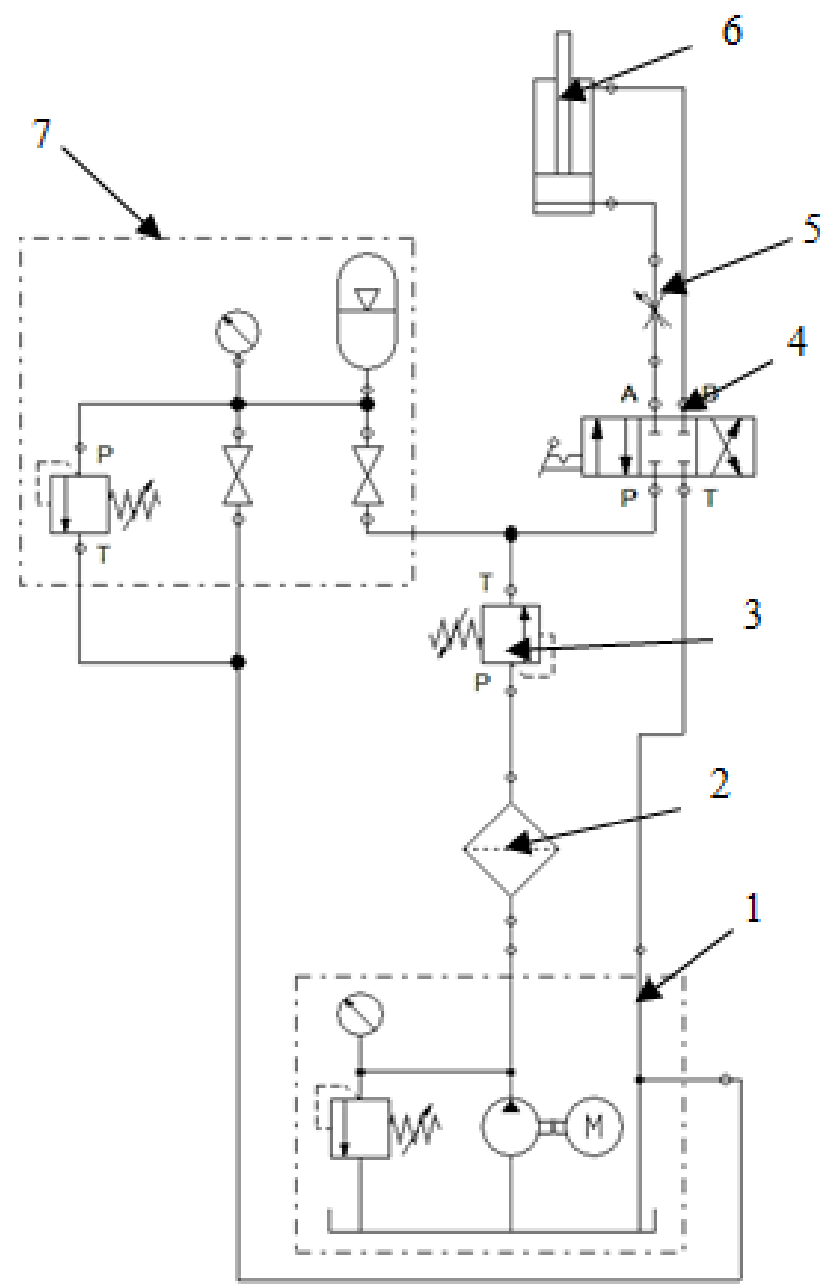

Figure 3. The hydraulic circuit of scissor lifting system

\subsection{Solid Model of the System}

The rigid model of the system was created in appropriate sizes by SolidWorks program. The system was designed as double scissors, single cylinder, working height of $2 \mathrm{~m}$, the platform length of $1.5 \mathrm{~m}$, and platform width of $1 \mathrm{~m}$. 
The double acting hydraulic cylinder in this system was used as a driver unit which has a piston diameter of $70 \mathrm{~mm}$ according to analysis. In the system, a rectangular profile material (St37) with dimensions of $80 \times 40 \times 5 \mathrm{~mm}$ was used as a scissor element. The cylindrical pins (St50) with a diameter of $40 \mathrm{~mm}$ and a length of $110 \mathrm{~mm}$ were preferred for combining the scissors together. The state of the first and last positions of the scissor lifting system was shown in Figure 4 . The operation of the system was also simulated depending on time in the SolidWorks program.

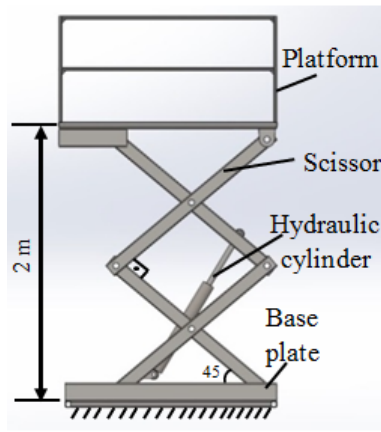

(a)

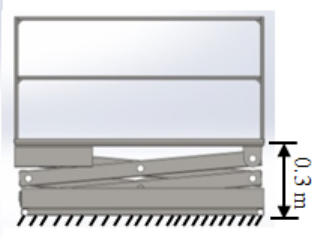

(b)
Figure 4. The scissor lifting system at opened (a) and closed position (b)

\subsection{Motion Analysis of the System}

In the scissor lifting system, the motion analysis was performed in order to select the piston type and determine the piston force $\left(F_{p}\right)$ before the analysis of the system by finite element method. The system was designed so that the scissors were positioned at an angle of $5^{\circ}$ in a fully closed position. Also, the scissors were positioned at an angle of $45^{\circ}$ at a fully open position. Hydraulic cylinder in the system was located at a different angle comparing with the scissors. When the starting angle was small such as the angle of $\beta$, the horizontal component of piston force $\left(F_{h}\right)$ was increased and the vertical component of piston force $\left(\mathrm{F}_{\mathrm{v}}\right)$ was decreased. This variation caused the increase of resultant force in order to obtain the required horizontal force for lifting the platform (Figure 5). Also, it increased the cost considerably because this situation required for selecting the larger diameter piston or a stronger pump. For this reason, the hydraulic cylinder was designed to be positioned with $\alpha=16.8^{\circ}$ angle for fully closed system. The minimum high of the system will increase when the angle $(\alpha)$ is higher than $16.8^{\circ}$. On the other hand, the hydraulic cylinder can not produce sufficient vertical force $\left(\mathrm{F}_{\mathrm{v}}\right)$ to lift the scissor when the angle $(\alpha)$ is lower than 16.8. For this reason, the angle was chosen as $16.8^{\circ}$.
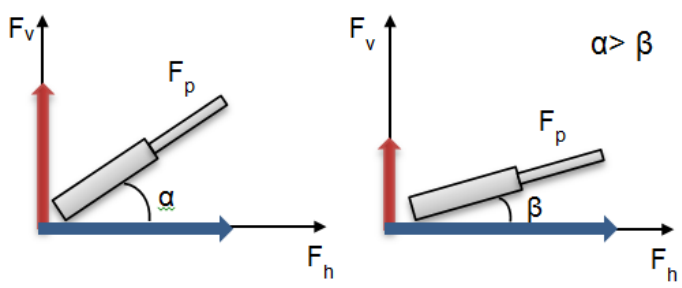

Figure 5. The symbolic variation of horizontal and vertical piston forces with piston angle
The variation of piston force $\left(\mathrm{F}_{\mathrm{p}}\right)$ with platform height was illustrated in Figure 6. The maximum value of piston force was obtained at first opening as $\sim 44700 \mathrm{~N}$. This force always acts in the same direction with the hydraulic cylinder. The piston diameter of hydraulic cylinder was determined as $\sim 70 \mathrm{~mm}$. The diameter of hydraulic cylinder was chosen according to the both buckling calculation and known systems. Thus, the pressure of pump should be selected as 116 bar in this system so that the hydraulic cylinder can produce this piston force $\left(\mathrm{F}_{\mathrm{p}}=44700 \mathrm{~N}\right)$.

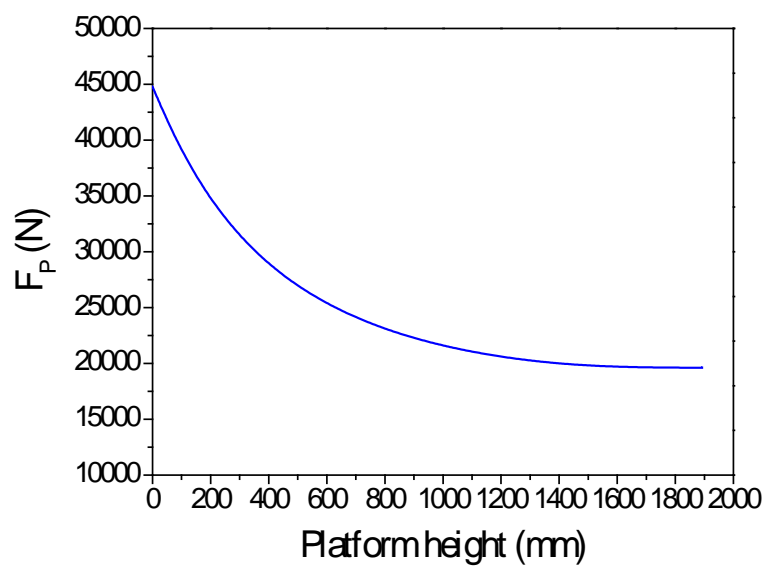

Figure 6. The variation of piston force with platform height

\subsection{Selection of Motor in the System}

In order to design a scissor lifting system, electric motor should be selected for hydraulic pump. Hence, volumetric flow rate $(\mathrm{Q})$ should be calculated by regarding stroke of cylinder $(\mathrm{L}=320 \mathrm{~mm})$, diameter of hydraulic cylinder $(\mathrm{d}=70 \mathrm{~mm})$, and the lifting time $(\mathrm{t}=15 \mathrm{~s})$ as given below;

$$
\mathrm{Q}=\mathrm{LA} / \mathrm{t}=\mathrm{L} \pi \mathrm{d}^{2} /(4 \mathrm{t})
$$

The volumetric flow rate $(\mathrm{Q})$ was determined as $0.295 \mathrm{~m}^{3} / \mathrm{h}$. By considering hydraulic efficiency of motor $\left(\eta_{\mathrm{h}}=0.75\right)$, pump pressure $(\mathrm{P} \cong 11600 \mathrm{kPa})$, motor power $(\mathrm{N})$ can be found as follows.

$$
\mathrm{N}=\mathrm{QP} /\left(3600 \eta_{\mathrm{h}}\right)
$$

By using this equation motor power $(\mathrm{N})$ was calculated as $1.26 \mathrm{~kW}$. For this reason, the electrical motor was selected for scissor lifting system which has a power of $1.5 \mathrm{~kW}$.

\subsection{Analysis of System by Finite Elements Method}

In order to analyze the scissor lifting system with finite elements method, firstly non-critical elements such as platform and base plate were removed from the system and simulation was completed in a shorter time. The system was fixed in four positions which were attached to the base plate (angle of $45^{\circ}$ ) in these positions. The weight of platform and the maximum load of the platform were $1000 \mathrm{~N}$ and $5000 \mathrm{~N}$, respectively. These loads were applied to the four points attached to the platform. The acting load 
on the cylinder $(\sim 19000 \mathrm{~N})$ is calculated in the motion analysis part of the program which kept the system steady in this position. It was actuated bilaterally from the connection points (3) of the piston (Figure 7).

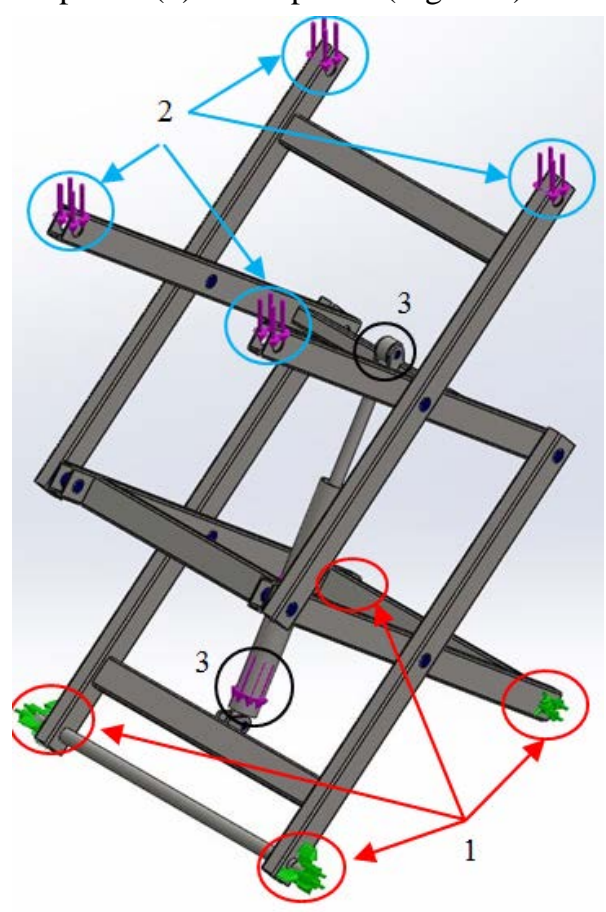

Figure 7. The loading points and fixed points for the analyzed model

A mesh structure of analyzed scissor lifting system after loading was shown in Figure 8. This was automatically created by the system at the high density and the high quality. The total number of nodes and the number of total element are determined as 96700 and 50625, respectively.

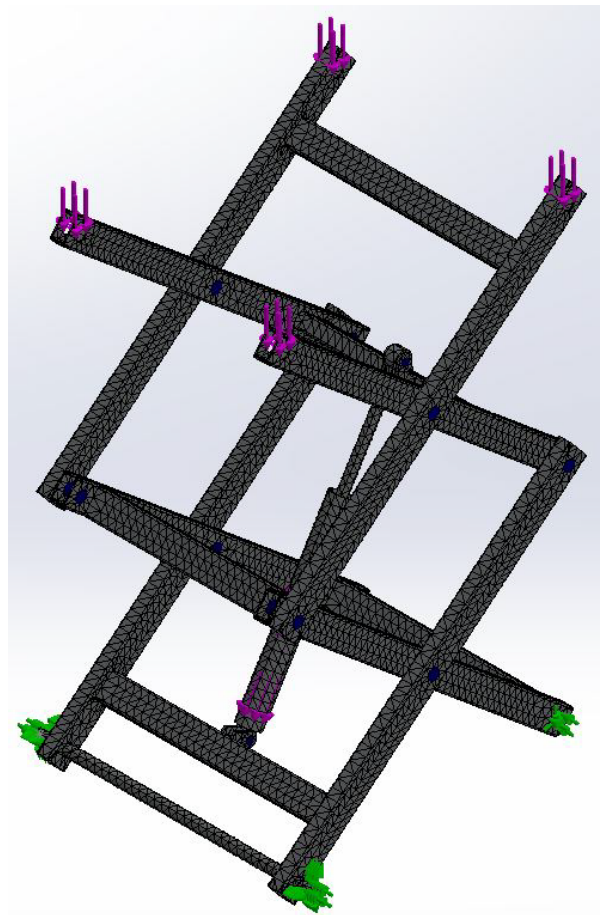

Figure 8. Mesh structure of analyzed system

\section{Results and Discussion}

As mentioned above SolidWorks simulation package was used to determine the stress distribution and the amount of deformation after mesh formation in the scissor lifting system. The stress distribution of the system was determined according to the maximum strain energy hypothesis (von-Mises) in the package program [6-8]. The maximum stress on the system was calculated as 56.916MPa which was observed at the Section-B as shown in Figure 9. The load acting on the cylinder caused the occurrence of the lower stress on the lower scissor (section-A).

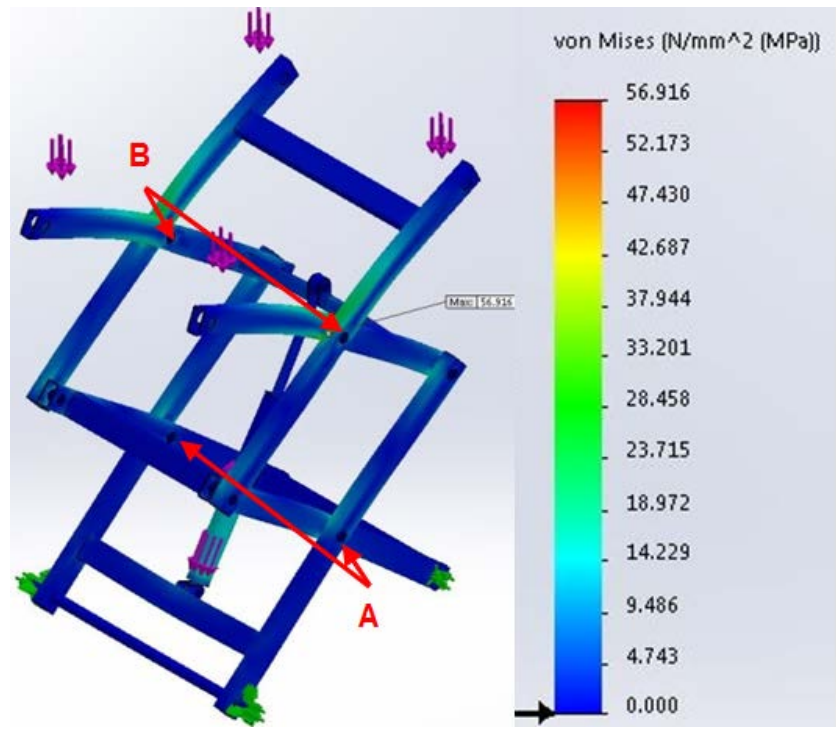

Figure 9. Stress distributions in scissor lifting system

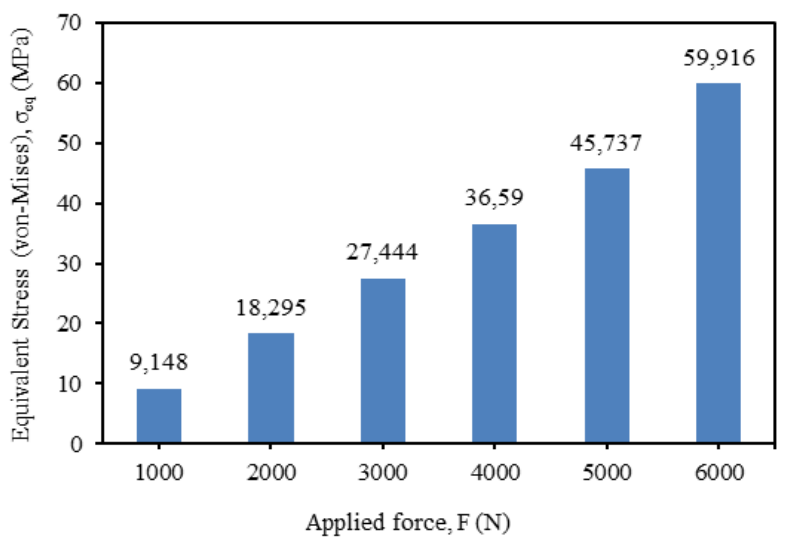

Figure 10. The variation of equivalent stresses with different loads on the platform

As shown in Figure 9 (at point B), the equivalent stresses at both second junctions of the scissors varied with the same amount when different loads were applied on the platform. This variation was illustrated in Figure 10. The equivalent stress $\left(\sigma_{\mathrm{eq}}\right)$ was determined as $9.148 \mathrm{MPa}$ according to the maximum shear strain energy with no load condition (only platform weight $\mathrm{F}=1000 \mathrm{~N}$ ). When the 
platform was loaded with a maximum load carrying capacity of $500 \mathrm{~kg}$ (the total applied force is $6000 \mathrm{~N}$ ), the equivalent stress $\left(\sigma_{\mathrm{eq}}\right)$ was measured as $59.916 \mathrm{MPa}$. It was found that the equivalent stress increased with the applied load on the platform, linearly.

The amount of deformation occurring in the elements of the scissors lifting system was given in Figure11. The maximum deformation $(0.6941 \mathrm{~mm})$ was found at the junction of the upper table and the upper scissors. In this analysis, it was assumed that the system was deformed in block form. The amounts of deformation were the same for each connection point as shown in Figure 8 (at point 2). In the lower scissor, a deformation $\left(3.818 \times 10^{-6} \mathrm{~mm}\right)$ was observed which could be ignored. It has been concluded that the deformation of both scissors does not create an obstacle to the operation of the system (during opening and closing).

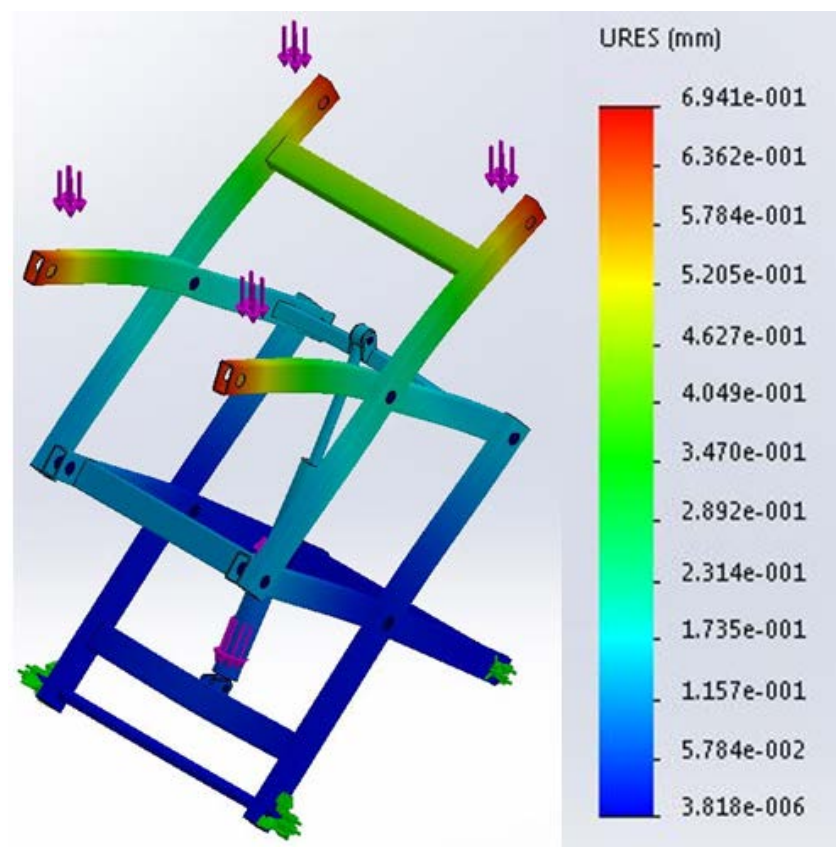

Figure 11. The amount of deformation in scissor lifting system

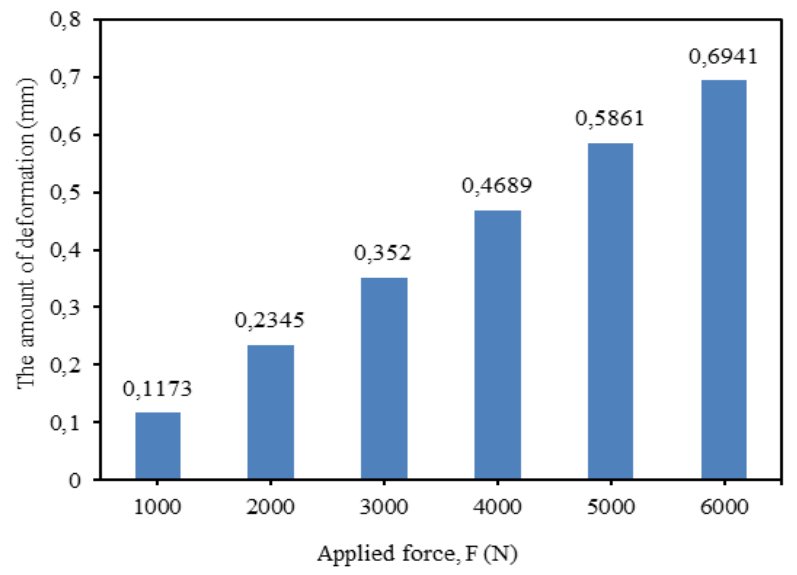

Figure 12. The deformation variation with different loads on the platform
Figure 12 showed the amount of deformation occurring at the junctions of the upper table and upper scissors under different loads in the platform. It was determined that the deformation was calculated as $0.1173 \mathrm{~mm}$ with no load condition. Also, the deformation was detected as $0.6941 \mathrm{~mm}$ when there was maximum load on the platform. The deformation increased by 6 times when the maximum load $(\mathrm{F}=6000 \mathrm{~N})$ was applied to the platform.

The safety factor (S) is defined as the ratio of yield stress to the maximum stress of selected component. As a result of analyzes carried out, the lowest safety coefficient $(\mathrm{S}=4.3$ ) was observed at the junction of the scissors when the scissors profiles were produced from the St37 material. The safety factor (S) of the pins which made of St52 material was found as 6.2. The minimum safety factor (S) should be 3 or more for the lifting systems. Hence, these safety factors are within acceptable limits for the system to be designed. [5].

\section{Conclusions}

In this study, the design and analysis of the scissor lifting system were performed with finite element method in SolidWorks program. The system had a working height of $2 \mathrm{~m}$ and a load carrying capacity of $500 \mathrm{~kg}$. The results obtained from the study performed were summarized as follows:

- In order to carry the load in the system safely, the scissors and pins were produced from the St37 and St52 material. Also, the solid model and simulation of the system were performed in SolidWorks program.

- The hydraulic circuit of the system was created with the Fluid-Sim program. In case of any pressure loss (power failure, engine failure, etc.), the hydraulic accumulator in the system began to start ensuring the operation of the system safely.

- The maximum stress of the system $\left(\sigma_{\mathrm{eq}}=56.916\right.$ $\mathrm{MPa}$ ) was determined at the connection points of the upper pair of scissors according to the von-Mises hypothesis.

- The maximum deformation occurred at the connection point of the upper shear and this value was determined as $0.6941 \mathrm{~mm}$. The amount of deformation in the same point was calculated as $0.1173 \mathrm{~mm}$ when there was no loading on the platform.

- A scissor lifting system has a double acting hydraulic cylinder with $400 \mathrm{~mm}$ stroke and $\varnothing 70$ $\mathrm{mm}$ cylinder diameter in order to open and close the system safely. Also, the maximum working pressure of the pump was determined as $~ 116$ bar.

- Electric motor was selected for this system according to the calculation of motor power as $1.5 \mathrm{~kW}$. 
- When the system was loaded with $500 \mathrm{~kg}$, the minimum safety coefficient (S) on the scissors was detected as 4.3. Also, the minimum safety coefficient on the pins was determined as 6.2.

- $\quad$ From the present study, it was predicted that the designed scissor lifting system designed should carry a $500 \mathrm{~kg}$ load to a height of $2 \mathrm{~m}$ safely.

\section{REFERENCES}

[1] T. Hongyou, Z. Ziyi. Design and simulation based on Pro/E for a hydraulic lift platform in scissors type, Procedia Engineering, Vol.16, pp.772-781, 2011.

[2] M.C. Şenel, Ş. Üstün. The Design of Scissor Lifting System, Gazi University, Faculty of Engineering Mechanical
Engineering Department, Graduation Thesis, 2009 (in Turkish).

[3] Y. Aksungur, M.Y. Nayir, E. Güneş. Senior design project: design and analysis of an aerial working platform, TOBB ETÜ, Ankara, 2012 (in Turkish).

[4] Y. Aksungur, M. A. Güler. Design and analysis of a scissor lift work platform, Engineer and Machinery, Vol. 54, No. 643, 36-46, 2013.

[5] SolidWorks Online Help, Dassault Systèmes, 2014.

[6] E. Koç, Machine Elements-Volume 1, Akademisyen Publisher, 6th Press, Ankara, 2015 (in Turkish).

[7] E. Koç, Machine Elements-Solved Problems, Akademisyen Publisher, 4th Press, Ankara, 2015 (in Turkish).

[8] C. G. Dengiz, M.C. Şenel, K. Yıldızlı, E. Koç. The Design of Scissor Lifting System and its Analysis with Finite Elements Method, International Conference on Material Science and Technology (IMSTEC'16), Nevşehir, Turkey (in Turkish). 